\title{
O Novo Estado Desenvolvimentista e o Governo Lula
}

\author{
Mansueto Almeida*
}

RESUMO - Este artigo debate os oito anos do governo Luiz Inácio Lula da Silva com o foco na análise da política fiscal e da política industrial. Argumenta-se que, apesar da maior expansão dos gastos sociais, o padrão de crescimento do gasto público do governo federal no Brasil é determinado muito mais pela Constituição Federal de 1988 do que pela eleição de um governo de esquerda. Quando se analisa a expansão dos gastos públicos do governo federal no Brasil desde 1991, chega-se à conclusão que há mais continuidade entre os diferentes governos do que uma suposta mudança de direção com a eleição do presidente Lula. No caso da política industrial, mostra-se que com eleição do presidente Lula o Estado voltou novamente a ter um papel ativo no fomento ao investimento privado por meio do Banco Nacional de Desenvolvimento Econômico e Social. Mostra-se no entanto, que apesar do surgimento do que se chama de "novo estado desenvolvimentista", um estado no qual a relação entre Estado e sociedade se dá de uma forma mais transparente e o crescimento seria tão baseado no investimento em capital físico e humano, na prática, no novo estado desenvolvimentista continua sendo mais fácil fomentar o capital privado do que expandir os gastos com educação.

Palavras-chave: Política fiscal. Política industrial. Estado desenvolvimentista. Inovação.

\section{INTRODUÇÃO}

Em 2002, o Brasil elegeu um ex-líder sindicalista, Luiz Inácio Lula da Silva, para ser Presidente da República e, assim, iniciou-se um novo período na história do Brasil. A eleição do presidente Lula naquela época foi marcada por uma elevada expectativa de mudanças profundas pelas quais passaria o Brasil, pois o Partido dos Trabalhadores, que sempre teve uma atuação aguerrida e vigilante na defesa do interesse público e na defesa da maior transparência nas ações do setor público, chegava ao poder.

Havia uma grande expectativa de como seria um governo de esquerda no Brasil e de como seria a gestão macroeconômica desse novo governo. O novo governo manteria o tripé da política econômica caracterizado pelo sistema de câmbio flutuante, regime de metas de inflação e a geração de superávits primários para o pagamento da dívida? Qual seria a nova proposta desse novo governo de esquerda para reduzir as desigualdades de renda e combater a pobreza? Seria possível esse novo governo modificar a discussão e aprovação de políticas públicas para tornar o processo de discussão e aprovação de leis no Congresso Nacional mais transparente?

Passados oito anos da experiência de um governo de esquerda no Brasil, talvez seja o momento adequado para que se tente responder as perguntas acima. Este artigo procura contri-

\footnotetext{
* Mestre em economia pela Universidade de São Paulo. É técnico de planejamento e pesquisa do IPEA. Endereço eletrônico: mansueto.almeida@ipea.gov.br.
} 
buir para este debate, analisando a política fiscal e política industrial do governo do presidente Luiz Inácio Lula da Silva. Do ponto de vista fiscal, o padrão de expansão do gasto público foi exatamente o mesmo observado ao longo dos anos 90 e, assim, não houve um modificação na direção da política fiscal, apesar de os programas sociais terem sido ampliados como seria esperado em um governo de esquerda.

Do ponto de vista setorial, não houve também mudanças bruscas ou rupturas com o passado. Apesar de o novo governo ter se preocupado desde o seu início com a definição de uma política industrial, essa política tornou-se cada vez mais ambígua ao longo dos últimos oito anos, consolidando setores e expandindo o crédito para empresas que já eram competitivas. Adicionalmente, ao invés dessa política aumentar a transparência quanto aos seus custos e benefícios, um problema comum do velho estado desenvolvimentista, a nova onda de intervenção do governo na promoção do desenvolvimento setorial ocorreu em um ambiente no qual os custos dessas políticas não foram em nenhum momento divulgados e debatidos com a sociedade. Assim, não houve a tão esperada ruptura seja na execução do gasto público, seja na execução das políticas industriais e de desenvolvimento setorial.

Este artigo defende a tese de que, apesar de toda a evolução na teoria econômica em relação aos fatores que explicam o crescimento econômico, na prática, os governos de centroesquerda na América Latina e Brasil ainda fazem uso extensivo de políticas e instrumentos identificados com o "velho estado desenvolvimentista" que caracterizou a história da América Latina no período de substituição de importações e que priorizava as políticas setoriais ao invés de políticas de fomento ao capital humano. Assim, apesar de ser cada vez mais comum alguns autores afirmarem que existe um novo estado desenvolvimentista (EVANS, 2008a, 2008b; TRUBEK, 2010) cujo fomento não se restringe ao investimento fixo, mas também aos gastos com educação, saúde e inovação, argumenta-se neste artigo que a evolução do velho estado desenvolvimentista para o novo estado desenvolvimentista é maior na teoria do que na prática. As seções seguintes detalham os argumentos expostos nesta introdução.

\section{POLÍTICA FISCAL 2003-2009: RUPTURA OU CONTINUIDADE?1}

Há no Brasil uma percepção comum do crescimento do tamanho do estado brasileiro pós-1988. No entanto, essa percepção está muitas vezes ligada a um crescimento rápido e excessivo do que se chama de gastos correntes. É quase consensual entre analistas econômicos e a imprensa em geral que o crescimento do gasto público no Brasil tem sido excessivo e que há uma urgência para se controlar o grande crescimento do custeio, tornando possível aumentar o

1 Ver Almeida, Giambiagi et al. (2006); Almeida; Pessoa (2010). 
investimento público sem que sejam necessários novos aumentos da carga tributária.

De 1991 a 2009, o gasto público do governo central (inclusive transferências a estados e municípios) passou de $13,7 \%$ para $22,3 \%$ do PIB, um crescimento de quase 0,48 ponto percentual do PIB a cada ano. Uma extrapolação linear simples desse comportamento para 2020 mostra que, se essa tendência se mantivesse pelos próximos dez anos, o gasto público não financeiro do governo federal seria de $27,6 \%$ do PIB, o que exigiria novos aumentos de carga tributária ao longo dos próximos anos. Esse crescimento do gasto público é algo específico do atual governo ou reflete um padrão que tem prevalecido no Brasil desde o início dos anos 90 ?

O Anexo 1 deste artigo mostra que, desde 1991, pode-se notar que os gastos com os benefícios do INSS foram aqueles que mais cresceram dentre os diversos componentes do crescimento do gasto público não financeiro do governo federal: 3,7 pontos percentuais do PIB ou $43 \%$ do aumento total. Se desse total descontarmos o crescimento do gasto público que corresponde à repartição de receitas com estados e municípios, o aumento dos gastos do INSS de 1991 a 2009 responde por mais da metade do crescimento do gasto público não financeiro do governo federal nesse período. O efeito do crescimento dos gastos com INSS no gasto público não muda muito se dividirmos esse período em dois: 1991-2002 e 2003-2009. Para esses dois períodos e excluindo a repartição de receita do governo federal com estados e municípios, a conclusão é a mesma: 55\% da expansão do gasto não financeiro do governo federal de 1991 a 2002 vem do aumento das despesas do INSS e, de 2003 a 2009, a participação dessa conta responde a $46 \%$ do crescimento do gasto.

Uma análise cuidadosa dos gastos públicos para o período mais recente, separando do custeio aqueles gastos para saúde, educação e políticas sociais, permite que se identifique melhor o padrão de expansão do gasto não financeiro do governo federal (\% do PIB). Como se observa na Tabela 1, os gastos que mais crescem desde 1999 são aqueles ligados ao INSS, gastos sociais e custeio dos ministérios da saúde e educação. O custeio restrito, gastos de custeio que sobram quando se retira os gastos sociais, previdência e custeio do ministério da saúde e educação, chega a cair ao longo dos últimos onze anos. Outra informação que se tira da Tabela 1 é o padrão de crescimento do gasto pós-2002, que é praticamente o mesmo que vigorava antes do governo Lula, sendo que o crescimento dos gastos sociais passou a ocorrer de forma mais rápida tanto pela expansão do número de beneficiários dos programas sociais quanto pela forte expansão do salário mínimo real que se intensificou a partir de 2003.

A política de valorização real do salário mínimo iniciada na segunda metade dos anos 90 e ampliada ao longo do governo Lula teve um forte impacto tanto no INSS quanto nos programas sociais. Em janeiro de 2000, o salário mínimo no Brasil (a valores de 2010) era de 
$\mathrm{R} \$ 288,75$ e, em agosto de 2010, esse valor já era de $\mathrm{R} \$ 510$, o que representa um crescimento de $87 \% \%^{2}$. Se por um lado esses aumentos foram positivos pelo impacto que trazem sobre o consumo, por outro lado, o efeito sobre o gasto público é elevado, exigindo uma carga tributária crescente para o seu financiamento.

TABELA 1 - GASTOS NÃO FINANCEIROS DO GOVERNO FEDERAL (\% DO PIB) 1999-2009

\begin{tabular}{l|c|c|c|c|c|c|c|c}
\hline ANO & DESPESA & PESSOAL & INSS & $\begin{array}{c}\text { CUSTEIO } \\
\text { RESTRITO }\end{array}$ & $\begin{array}{c}\text { CUSTEIO SAÚDE } \\
\text { E EDUCAÇÃO }\end{array}$ & SOCIAIS & INVEST. & OUTROS \\
\hline 1999 & $14,06 \%$ & $4,47 \%$ & $5,50 \%$ & $2,17 \%$ & $0,75 \%$ & $0,59 \%$ & $0,50 \%$ & $0,08 \%$ \\
2000 & $14,44 \%$ & $4,57 \%$ & $5,58 \%$ & $2,07 \%$ & $0,90 \%$ & $0,58 \%$ & $0,66 \%$ & $0,08 \%$ \\
2001 & $15,28 \%$ & $4,80 \%$ & $5,78 \%$ & $2,25 \%$ & $0,91 \%$ & $0,65 \%$ & $0,81 \%$ & $0,08 \%$ \\
2002 & $15,75 \%$ & $4,81 \%$ & $5,96 \%$ & $2,30 \%$ & $0,90 \%$ & $0,78 \%$ & $0,92 \%$ & $0,08 \%$ \\
2003 & $14,97 \%$ & $4,46 \%$ & $6,30 \%$ & $1,91 \%$ & $0,91 \%$ & $0,88 \%$ & $0,40 \%$ & $0,10 \%$ \\
2004 & $15,33 \%$ & $4,31 \%$ & $6,48 \%$ & $1,88 \%$ & $1,06 \%$ & $1,11 \%$ & $0,37 \%$ & $0,11 \%$ \\
2005 & $16,11 \%$ & $4,30 \%$ & $6,80 \%$ & $2,02 \%$ & $1,10 \%$ & $1,27 \%$ & $0,51 \%$ & $0,11 \%$ \\
2006 & $16,78 \%$ & $4,45 \%$ & $6,99 \%$ & $1,95 \%$ & $1,13 \%$ & $1,42 \%$ & $0,74 \%$ & $0,10 \%$ \\
2007 & $16,85 \%$ & $4,37 \%$ & $6,96 \%$ & $1,87 \%$ & $1,20 \%$ & $1,52 \%$ & $0,83 \%$ & $0,09 \%$ \\
2008 & $16,51 \%$ & $4,35 \%$ & $6,64 \%$ & $1,65 \%$ & $1,25 \%$ & $1,57 \%$ & $0,94 \%$ & $0,12 \%$ \\
2009 & $18,33 \%$ & $4,84 \%$ & $7,17 \%$ & $1,85 \%$ & $1,38 \%$ & $1,88 \%$ & $1,09 \%$ & $0,13 \%$ \\
\hline
\end{tabular}

FONTE: Tesouro Nacional e SIAFI. Elaboração própria.

Obs: A coluna de despesa total não inclui despesas com juros nem repartição de receita.

O padrão do gasto fiscal no Brasil desde 2002 é, basicamente, o mesmo que prevaleceu desde o início dos anos 90 e reflete muito mais decisões tomadas pela sociedade brasileira no final dos anos 80, quando a nova Constituição Federal foi elaborada, do que por mudanças decorrentes da eleição de um governo de esquerda em 2002. É claro que o padrão de crescimento dos gastos públicos no Brasil é sensível à expansão do salário mínimo e, assim, o governo Lula poderia ter sido mais parcimonioso no reajuste do salário mínimo como também na concessão de reajustes aos funcionários públicos. No entanto, a diferença entre o padrão do gasto fiscal antes e depois do governo Lula é mais de magnitude do que de direção.

Infelizmente, o governo Lula não deu a mesma importância à agenda de reformas estruturais efetuadas ao longo dos três primeiros anos do governo. O crédito consignado, a nova Lei de Falências (Lei 11.101/2005) e a Lei de Alienação Fiduciária (Lei 10.931/2004) foram medidas corretas. Como também foi a minirreforma da previdência pública de 2003 que, ao instituir a contribuição sobre os inativos do setor público, reduziu o efeito que a equiparação dos salários dos servidores ativos e inativos tem nas contas públicas.

Em relação às transferências sociais, é importante ressaltar, segundo Lindert (2004), que não há correlação negativa entre essas transferências e crescimento do PIB per capita (ou

2 É interessante lembrar que um dos temas debatidos na campanha eleitoral de 2002, no Brasil, era quando o salário mínimo atingiria o valor de US\$100. No início de 2011, caso venha se confirmar o novo valor do salário mínimo de R \$540,00, esse novo salário mínimo será de US\$318 (ao câmbio de 1 US $\$=R \$ 1,70$ ). Ou seja, o Brasil mais do que triplicou o salário mínimo em dólar em menos de uma década. 
nível do PIB per capita) para um grupo de países hoje de alta renda ${ }^{3}$. Como normalmente o tamanho do Estado (\% do PIB) está ligado ao aumento das transferências sociais, o autor chega à conclusão que maiores gastos sociais que aumentam o peso do Estado na economia não ocasionam, necessariamente, menor crescimento. No entanto, no caso do Brasil, segundo o próprio Lindert afirmou em entrevista à revista Veja (edição 1.920 de 27/08/2005), apesar dos gastos sociais elevados, eles não são muito eficientes já que acabam favorecendo aos que não são pobres, como seria o caso dos elevados gastos com previdências (pública e privada). Assim, haveria ainda em países como o Brasil e na América Latina espaço para melhorar o seu sistema de distribuição de renda, independente do tamanho do Estado e do nível da carga tributária.

É justamente essa agenda que não avançou, como se esperava do governo Lula, apesar do progresso que foi a implementação do Bolsa Família, um programa barato (0,4\% do PIB) e bem focalizado. No entanto, o foco demasiado em uma política de crescimento baseada em reajustes reais do salário mínimo e uma atuação tímida na melhoria do gasto e na qualidade da educação não sinalizam o que se esperaria de um governo de esquerda. Adicionalmente, as tentativas frustradas de melhorar a progressividade da arrecadação por meio de uma reforma tributária que não ocorreu mostra que tanto do lado da receita quanto da despesa fiscal, houve mais continuidade do que ruptura.

Em resumo, há mais continuidade na área fiscal e tributária antes e depois do governo Lula do que mudanças profundas na composição do gasto público sendo que, a partir de 2008, iniciou-se uma agenda que tornou mais obscuro o debate de custo-benefício das políticas públicas, uma vez que a política industrial passou a ser cada vez mais dependente de uma estrutura de financiamento baseada no aumento da dívida pública e o cálculo do resultado primário passou a estar cada vez mais sujeito a truques contábeis (ALMEIDA, 2010).

\section{POLÍTICA INDUSTRIAL E INOVAÇÃO ${ }^{4}$}

O tema política industrial é de grande controvérsia na literatura econômica. Parte dessa controvérsia decorre do simples fato de que, normalmente, a ideia de política industrial vai contra um dos conceitos mais antigos e respeitados da teoria econômica: o conceito de vantagens comparativas do economista David Ricardo. Segundo esse economista, cada país deveria se concentrar na produção daqueles produtos que tivessem alguma vantagem comparativa ${ }^{5}$ e, 3 Os gastos sociais considerados pelo autor incluem os benefícios para os idosos, seguro desemprego, pensões públicas sem contribuição, subsídios a moradias populares, programas de combate a pobreza, inclusive transferências de renda, e gastos com saúde pública.

4 Ver (Almeida, 2009).

5 Um país tem vantagem comparativa na produção de um bem se o custo de oportunidade na produção do bem em termos de outros bens é mais baixo que em outros países. Ver (Krugman; Obstfeld, 2001), p. 14-15. 
por meio do comércio internacional, todos os países poderiam aumentar o consumo e o bemestar da população.

No entanto, o conceito de vantagens comparativas é um conceito estático, depende do estado das artes hoje e, assim, nada indica que um país não possa desenvolver expertise em determinadas atividades que hoje simplesmente não existem naquele país. Rodrick (2004) argumenta que a "política industrial do séc. XXI" deve ser entendida como um processo de descoberta no qual os governos poderiam incentivar diversas atividades (e inovações) cujos agentes econômicos não sabem ex ante se essas novas atividades, novos produtos e mesmo novos processos seriam economicamente viáveis. Pelo argumento de Rodrick, a descoberta de novos produtos e processos é um caso típico no qual os benefícios sociais dessas descobertas são maiores que os benefícios privados e os custos elevados para os empresários individuais. Assim, sem o fomento do Estado, os gastos com inovação e o processo de descoberta de novas atividades seriam menores do que o nível ótimo desejado pela sociedade.

A razão teórica para esse tipo de política industrial mais focada na descoberta de atividades que os países não sabem ex ante se serão ou não competitivas é completamente diferente do que normalmente se denomina de política industrial, quando o governo concede crédito subsidiado para atividades econômicas que já existem em um determinado país e cujos sinais de mercado já mostram se aquela atividade é ou não competitiva. Por exemplo, quando o governo concede subsídios para reduzir o custo de produção de calçados sem alterar o processo de produção do setor, o governo estaria apenas reduzindo artificialmente os custos de produção e criando uma dependência permanente desse setor aos subsídios governamentais. Isso é completamente diferente, por exemplo, de o governo incentivar o desenvolvimento de novos métodos de produção na manufatura de calçados, o que poderia levar a descoberta de um novo produto ou um novo processo de produção que ocasionasse uma redução permanente do custo de produção.

Assim, mesmo os críticos da tradicional política industrial dos anos 60 e 70 são favoráveis a "política industrial do séc. XXI" que seria focada muito mais na descoberta de novos produtos e processos do que na redução pura e simples dos custos de produção pelo uso de subsídios. Dito isso, qual foi a política industrial do governo Luiz Inácio Lula da Silva?

No Brasil, com a eleição do presidente Lula, em 2002, tem início um grupo de trabalho já no seu primeiro ano de governo, em 2003, com o intuito de criar a nova política industrial. Em 2004, o governo lança a Política Industrial, Tecnológica e de Comércio Exterior (PITCE). Essa política consistia em um plano de ação do Governo Federal que tinha como objetivo o aumento da eficiência da estrutura produtiva, aumento da capacidade de inovação das empresas 
brasileiras e expansão das exportações. No entanto, esse tipo de política com o foco em inovação foi muito criticada pela falta de clareza e de objetivos relativos aos demais setores, dentre os quais, aqueles que o Brasil já têm vantagens comparativas. Assim, talvez em decorrência dessas críticas, o governo tenha decidido lançar uma segunda política industrial em 2008, a Política de Desenvolvimento Produtivo (PDP).

Os vários diagnósticos que existiam sobre política industrial no Brasil sempre abordavam não uma, mas diversos tipos de políticas industriais, a depender das características do setor da economia a ser incentivado. A definição de política industrial tem sempre um dilema implícito entre "o que se quer ser" - um país com uma estrutura produtiva especializada em produtos de alta tecnologia com exportações de produtos e serviços de alto valor agregado - e "o que se é" - um país com estrutura produtiva diversificada com vantagens competitivas na produção de produtos agropecuários, minerais, siderúrgicos e na cadeia de petróleo e gás.

O dilema acima pode ser conciliado com uma estratégia de política industrial mais ampla na linha sugerida por Fleury e Fleury (2004), que destaca várias estratégias de política industrial, desde a promoção de empresas maquiladoras até a criação de setores intensivos em tecnologias. Essa ideia pragmática de política industrial talvez seja o que esteja por trás da Política de Desenvolvimento Produtivo (PDP), adotada pelo governo Lula em 2008, que procurava incentivar diversos setores da indústria brasileira.

Há pelo menos duas grandes contradições nas políticas industriais modernas, e a PDP não é exceção. Primeiro, as metas da PDP eram todas metas de curto prazo para 2010, coincidentes com o ciclo eleitoral. Acontece que a maioria das mudanças que se esperam de uma verdadeira política industrial só podem ser avaliadas no longo prazo. Essa é a grande inconsistência temporal das políticas industriais adotadas por governos democráticos: a mudança estrutural que se deseja com a política industrial é, necessariamente, uma política de longo prazo, mas os governos precisam mostrar resultados no curto prazo para que sejam premiados pelo "sucesso" dessas políticas e possam continuar com a sua implementação. Segundo, o sucesso de curto prazo decorrente da promoção deliberada de processos de fusões e aquisições (F\&A) com vistas à criação de empresas brasileiras globais, consolida o modelo de inserção internacional que o governo quer mudar, tornando mais difícil conciliar os objetivos de curto (aumento da taxa de investimento e das exportações) com os de longo prazo (mudança na estrutura produtiva). No caso da PDP, ao que parece, mais do que modificar a atual estrutura da indústria brasileira ou mesmo incentivar maiores gastos em P\&D, a política industrial está promovendo empresas e

6 O foco da PDP em vários setores industriais é um dos pontos elogiados pela Federação das Indústrias do Estado de São Paulo (FIESP). Ver seção 2 (FIESP, 2008). 
setores nos quais o Brasil já é competitivo e consolidando a atual estrutura industrial, um movimento que fatalmente ocorreria com ou sem política industrial.

Quando se olha os maiores desembolsos do BNDES em 2008 e 2009 constata-se, de forma clara, que há uma predominância dos empréstimos para empresas em setores nos quais o Brasil já tem uma clara vantagem comparativa. Dos dez maiores empréstimos para o setor industrial efetuados diretamente pelo BNDES em 2008 e 2009, destacam-se os empréstimos para frigoríficos, empresas do ramo de alimentos, bebidas e usinas de álcool, além dos empréstimos diretos para a Petrobras, que foram de R $\$ 23,4$ bilhões apenas em 2009. Na verdade, a política de empréstimos do BNDES antes da introdução da política industrial era mais diversificada do que no período recente, como se pode observar nas tabelas abaixo?

TABELA 2 - DESEMBOLSOS DO BNDES - INDÚSTRIA DE TRANSFORMAÇÃO - R\$ MILHÕES

\begin{tabular}{lrr|r|r}
\hline & \multicolumn{1}{c}{$\mathbf{2 0 0 2}$} & \multicolumn{1}{c}{$\mathbf{2 0 0 7}$} & \multicolumn{1}{c}{$\mathbf{2 0 0 8}$} & \multicolumn{1}{c}{$\mathbf{2 0 0 9}$} \\
\hline Produtos Alimentícios & $2.090,0$ & $4.368,8$ & $9.543,9$ & $8.034,0$ \\
Celulose e Papel & $1.272,6$ & $1.808,5$ & 857,7 & $3.567,7$ \\
Coque, Petróleo e Combustível & 183,3 & $1.798,0$ & $3.145,6$ & $23.238,4$ \\
Metalurgia & $1.019,5$ & $3.119,8$ & $3.209,2$ & $4.488,0$ \\
Outros & $12.591,6$ & $14.300,3$ & $18.953,9$ & $20.974,1$ \\
Indust. De Transformação & $17.157,0$ & $25.395,4$ & $35.710,3$ & $60.302,2$ \\
\hline
\end{tabular}

FONTE: BNDES.

TABELA 3 - \% DO TOTAL DA INDÚSTRIA DE TRANSFORMAÇÃO

\begin{tabular}{lrrrrr} 
& $\mathbf{2 0 0 2}$ & $\mathbf{2 0 0 7}$ & $\mathbf{2 0 0 8}$ & $\mathbf{2 0 0 9}$ \\
\hline Produtos Alimentícios & $12 \%$ & $17 \%$ & $27 \%$ & $13 \%$ \\
Celulose e Papel & $7 \%$ & $7 \%$ & $2 \%$ & $6 \%$ \\
Coque, Petróleo e Combustível & $1 \%$ & $7 \%$ & $9 \%$ & $39 \%$ \\
Metalurgia & $6 \%$ & $12 \%$ & $9 \%$ & $7 \%$ \\
Outros & $73 \%$ & $56 \%$ & $53 \%$ & $35 \%$ \\
Indust. De Transformação & $100 \%$ & $100 \%$ & $100 \%$ & $100 \%$ \\
\hline
\end{tabular}

FONTE: BNDES.

Os desembolsos do BNDES seguem a lógica de demanda por crédito e, assim, o banco tem sido mais eficaz em promover empresas em setores que já somos competitivos e não precisariam de tanto suporte do poder público. É possível afirmar que, com ou sem política industrial, o perfil dos empréstimos do BNDES não seria muito diferente do que foi nos últimos anos. O que se destaca na política industrial do Brasil é muito mais o aumento da oferta de crédito subsidiado do que o fomento à descoberta de novos processos de produção e/ou atividades na linha defendida por Rodrick (2004).

7 Pesquisa recente do BNDES sobre as perspectivas de investimento na indústria apontam também para uma concentração setorial do investimento para os próximos anos. De acordo com o BNDES, os setores de maiores investimentos no período de 2010-2013 serão os seguintes: (1) Petróleo e Gás (R \$ 295 bilhões); (2) Extrativa Mineral ( $\mathrm{R} \$ 52$ bilhões); (3) Siderurgia ( $\$ 44$ bilhões); e (4) Petroquímica ( $\$ 36$ bilhões). Esses quatro setores responderão por $\mathrm{R} \$ 427$ bilhões $(85,5 \%$ ) de um total de $\mathrm{R} \$ 499$ bilhões de investimento na indústria de 2010 a 2013 , de acordo com levantamento realizado junto as áreas operacionais do BNDES. Ver Puga; Meirelles (2010). 
Por outro lado, para um país que precisa urgentemente aumentar o seu esforço inovador, acontece algo inusitado. Apesar de todas as mudanças já efetuadas para aumentar os dispêndios com inovação nos últimos oito anos (ALMEIDA, 2009), os Fundos Setoriais (FS), que são os principais instrumentos de fomento à inovação no Brasil, não conseguem executar a totalidade dos recursos anuais disponíveis. Como se observa no Gráfico 1, apesar do aumento contínuo no orçamento dos FS, menos de 40\% dos recursos são de fato gastos anualmente com o fomento à P\&D.

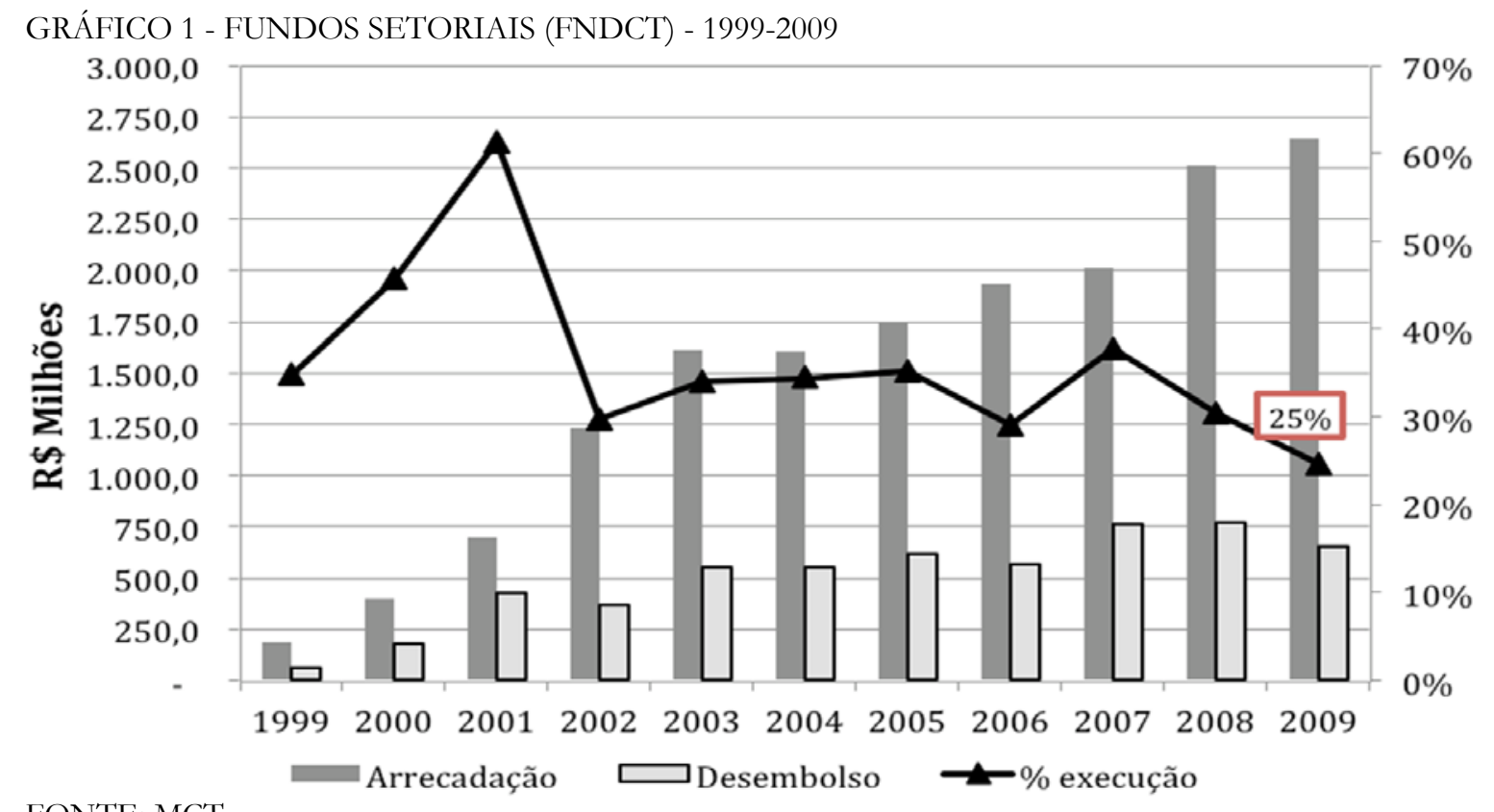

FONTE: MCT.

Essa baixa execução dos recursos dos FS pode até ajudar a entender os resultados da última edição da PINTEC. Essa pesquisa mostra que houve um aumento no percentual de empresas que inovam em produtos e processos para empresas, mas o percentual das que inovam em produto ou processo para o mercado ainda é semelhante ao que era há dez anos, o que deixa dúvidas do real sucesso da política industrial em aumentar o esforço inovador das empresas brasileiras. O maior crescimento da inovação em processos para as empresas sinaliza muito mais a incorporação de novas máquinas ao parque produtivo, que foi e continua sendo a principal forma de inovação das firmas no Brasil.

Essa mesma pesquisa mostra também que as empresas com mais de 500 empregados na indústria são muito mais inovadoras em produto e processo do que as de menor porte. Será que esse fato indicaria que o fomento à formação de grandes grupos empresariais pelo BNDES seria correto? A reposta é não porque aquilo que o BNDES faz vai muito além do estímulo ao aumento do porte das empresas. Na realidade, em vários segmentos da indústria brasileira, 
como papel e celulose, setor de alimentos (frigoríficos), setor químico e o setor de telecomunicação, houve uma clara política de concentração, sem que fosse divulgado os benefícios para a população e não apenas para os acionistas das empresas incentivadas por essa estratégia de concentração. Se concentração de mercado fosse sinônimo de eficiência e oferta de produtos de melhor qualidade, o México teria um dos serviços de telefonia fixa e serviços de banda larga mais eficientes do mundo, já que uma empresa mexicana tem quase o monopólio nesse setor naquele país ${ }^{8}$.

TABELA 4 - INOVAÇÃO DE PRODUTO E PROCESSO NA INDÚSTRIA - BRASIL

\begin{tabular}{l|r|r|rr|r}
\hline \multicolumn{1}{|c|}{ PINTEC } & $\begin{array}{c}\text { Produto novo } \\
\text { para empresa } \\
\text { (a) }\end{array}$ & $\begin{array}{c}\text { Produto novo para o } \\
\text { mercado brasileiro } \\
\text { (b) }\end{array}$ & $\begin{array}{c}\text { Processo novo } \\
\text { para empresa } \\
\text { (c) }\end{array}$ & $\begin{array}{c}\text { Processo novo para } \\
\text { o mercado brasileiro } \\
\text { (d) }\end{array}$ \\
\hline $1998-2000$ & 17,6 & 4,1 & 25,2 & 2,8 \\
$2001-2003$ & 20,3 & 2,7 & 26,9 & 1,2 \\
$2003-2005$ & 19,5 & 3,2 & 26,9 & 1,7 \\
$2006-2008$ & 22,9 & 4,1 & 32,1 & 2,3 \\
\hline
\end{tabular}

FONTE: IBGE, PINTEC.

A atuação do BNDES está longe de ser passiva, já que o banco atua tanto na operação de empréstimos quanto como investidor das novas empresas multinacionais brasileiras para ajudar no seu processo de internacionalização. Em 2008, por exemplo, o grupo JBS/Friboi pegou $\mathrm{R} \$ 1,1$ bilhão de empréstimos com o BNDES; em 2009, mais $\mathrm{R} \$ 3,5$ bilhões; e mais $\mathrm{R} \$ 200$ milhões em 2010. Como o JBS comprou o grupo Bertin, que tinha recebido R $\$ 2,5$ bilhões de empréstimos diretos do BNDES, em 2008, e mais R 200 milhões em 2009, todos esses empréstimos totalizam $\mathrm{R} \$ 7,5$ bilhões em um prazo de três anos. Mas, além desses empréstimos diretos, O BNDESpar comprou participação no JBS e no grupo Bertin, que hoje são a mesma empresa.

De acordo com o balanço patrimonial do BNDES de junho de 2010, o banco possuía 17,32\% do JBS; algo como R \$ 3,9 bilhões (participação societária do custo de dezembro de 2009). Essa participação coloca o JBS entre aquelas empresas nas quais o BNDESpar é um grande acionista, ocorrendo o mesmo com a Eletrobras ( $\mathrm{R} \$ 4,3$ bilhões), Vale $\mathrm{S} / \mathrm{A}$ ( $\mathrm{R} \$ 3,7$ bilhões), Valepar (R \$ 2,6 bilhões), FIBRIA (R \$ 2,3 bilhões), Telemar ( $\$$ 1,4 bilhão), Petrobras ( $\mathrm{R}$ \$ 1,2 bilhão), e Marfrig ( $\mathrm{R} \$ 987$ milhões), entre outros.

8 A cientista política Denise Dresser é uma das maiores críticas do processo de concentração do setor de telecomunicações ocorrido no México no início dos ano 90. Segundo essa pesquisadora, o sucesso da Telmex, de propriedade do empresário Carlos Slim, um dos três homens mais ricos do mundo, decorreu de uma política do governo de criar uma grande empresa nacional doméstica no setor de telecomunicação. O resultado dessa política foi a criação de uma empresa nacional (Telmex), que tem mais de 70\% do mercado de telefones fixos e celulares no México, e um dos piores e mais caros serviços de telefonia e banda larga do mundo. Ver Dresser (2009); Wright (2009). 
Existe alguma evidência empírica de que os ganhos dessa política de concentração setorial e de formação de grandes grupos empresariais traz ganhos sociais maiores que ganhos privados? Não há no momento nenhuma evidência de que isso esteja acontecendo e as chamadas macrometas da política industrial baseiam-se em indicadores (taxa de investimento, aumento das exportações, gastos privados em P\&D e número de pequenas empresas exportadoras) que são irrelevantes para se medir o real sucesso da política industrial. Sabe-se no entanto que as chamadas campeãs nacionais são, em geral, formadas por empresas em setores que já eram competitivos na América Latina e Brasil no início da década atual, caracterizados pelo uso intensivo de recursos naturais, e que mesmo após a abertura de capital dessas novas multinacionais verde-amarela, o seu controle ainda continua nas mãos dos antigos grupos familiares (ver Schneider, 2009).

O que o governo tem feito com certo "sucesso" é ajudar esses grupos a se tornarem maiores, sem exigência alguma de contrapartidas; o que torna a política industrial brasileira diferente do próprio modelo que lhe serve de inspiração para a formação de grandes grupos empresariais brasileiros: a política industrial dos anos 60 da Coreia do Sul (ver AMSDEN, 1989; 2001). No caso da Coreia do Sul, os incentivos eram direcionados para que os grandes grupos empresariais utilizassem sua expertise de planejamento, exportação, treinamento de mão de obra etc., para tentar investir em setores completamente novos para a empresa com a ajuda do governo. No caso do Brasil, o que predomina é a concessão de crédito subsidiado para as empresas fazerem mais do mesmo, apesar dos sinais de mercado já indicarem que o Brasil tem vantagem comparativa em diversas atividades que se destacam no acesso aos recursos do BNDES - agribusiness, mineração, extração de petróleo em águas profundas, siderurgia etc.

No entanto, um dos maiores problemas relativos à política industrial é a cada vez mais complicada relação entre Tesouro Nacional e BNDES. É legítimo que um governo queira adotar políticas setoriais, mas é necessário que se reconheça que políticas de fomento setorial não são mais ou menos importantes que políticas de fomento à educação ou saúde. Assim, a mesma exigência de transparência para políticas focadas no capital humano deveriam valer para as políticas de fomento ao capital físico, como será abordado em seguida.

\section{O VELHO VERSUS O NOVO ESTADO DESENVOLVIMENTISTA}

Recentemente, alguns autores têm escrito sobre um novo conceito que alguns têm chamado de o "novo estado desenvolvimentista" (EVANS, 2008a; EVANS, 2008b; TRUBEK, 2010). O velho estado desenvolvimentista seria aquele mais voltado para facilitar o processo de transformação de economias de base primária exportadora para uma economia industrializa- 
da, cabendo ao Estado o duplo papel de atuar em alguns setores como investidor e em outros subsidiando e protegendo o investimento privado. No velho estado desenvolvimentista, ocorre o que Kohli (2004) chama de "estado capitalista politicamente coeso", caracterizado por um poder central forte, uma forte aliança entre a elite industrial e o governo, algum controle ou regulação dos trabalhadores e a existência de uma burocracia eficiente com servidores recrutados por critérios meritocráticos. Esse foi o Brasil do período de substituição de importação e a Coreia no auge de sua política industrial.

Esse tipo de Estado pode ocorrer com democracia (apesar de um certo controle na organização dos trabalhadores) ou em uma ditadura. No tipo que caracterizou o "velho estado desenvolvimentista", o foco do crescimento se dava por meio de incentivos ao capital físico, que seria o motor do crescimento, e considerações sobre distribuição de renda ou a realocação de gastos para o financiamento da educação, saúde e inovação eram considerados secundários e dependiam da boa vontade do governante de plantão. Como já enfatizado, a aliança política do Estado no velho Estado Desenvolvimentista se dava, preponderantemente, com a elite industrial. Peter Evans (1995) cunhou o termo "parceira e autonomia" para descrever esse relação próxima do Estado com a elite industrial que, segundo esse autor, seria importante para entender experiências bem sucedidas de política industrial.

Segundo Evans, para que o Estado pudesse ajudar o setor privado no processo de desenvolvimento de novas atividades, precisaria construir uma rede de relações com a elite empresarial para entender que tipo de apoio o setor privado necessitava e mesmo quais políticas deveriam ser alteradas para aumentar a eficácia desse apoio. O Estado precisaria estar inserido (embedded) em uma rede de relações com o setor privado. Por outro lado, para ser parceiro do setor privado precisaria ter nos seus quadros uma burocracia weberiana, com funcionários recrutados por critérios meritocráticos e bem pagos, o que dificultaria a captura (corrupção) pelo setor privado. Ou seja, o Estado precisa ser autônomo para que sua relação de apoio e parceira com o setor privado não termine em conluio. O Estado para ser desenvolvimentista precisa reunir essas duas funções simultaneamente: ser autônomo e estar inserido em uma rede de relações com o setor privado, como foi o caso de países como Japão e mesmo Coreia.

Entendido o conceito do "velho estado desenvolvimentista", o que caracterizaria "o novo estado desenvolvimentista"? O desenvolvimento da teoria econômica desde os anos 60 alterou o conhecimento dos fatores que explicariam o desenvolvimento econômico. Os dois artigos que revolucionaram o pensamento econômico na área de crescimento foram os do economista Paul Romer (1986) e o do economista Robert Lucas (1988). Esses artigos destacavam, respectivamente, o papel do incentivo à inovação e a importância do capital humano na 
promoção do crescimento da renda per capita. Romer conseguiu, pela primeira vez, modelar rendimentos crescentes nos modelos de crescimento e explicou que esses rendimentos crescentes decorreriam da contribuição de novas "ideias" no uso mais produtivo dos fatores de produção: capital e trabalho. No caso de Lucas, ele dividiu o fator de produção trabalho em duas categorias: aquela que representa habilidades gerais e outra parte que depende dos investimentos acumulados em educação. Quanto maior o investimento em educação, menor seria a necessidade da outra categoria de trabalho para se obter o mesmo produto.

Essas novas ideias na campo da teoria econômica foram reforçadas pelo ressurgimento de governos democráticos nos países Latino-Americanos. Nem do ponto de vista teórico, nem tão pouco do ponto de vista político, fazia sentido colocar metas de crescimento da taxa de investimento em capital físico como o único e mais importante indicador para promover o crescimento de economias. Assim, começa a migração para o "novo estado desenvolvimentista". Nesse novo Estado, caracterizado pela existência de várias classes organizadas e poder político fragmentado, o governante não consegue apoio político se aliando apenas à elite industrial e, assim, tem que atender demandas simultâneas para favorecer sua ampla base eleitoral. Nesse tipo de Estado, o desejo de crescer mais rápido conflita com o desejo imediato por políticas distributivas. O Estado não controla a sociedade e, portanto, não pode priorizar a promoção da indústria como sendo mais importante que políticas de distribuição de renda. Esse é o Brasil de hoje e a Índia desde sua independência, onde o Estado democrático tenta conciliar as diversas demandas da sociedade.

Do ponto de vista teórico, o novo estado desenvolvimentista trabalha também com um conceito muito mais amplo de desenvolvimento. Sabe-se agora que investimentos no capital humano são tão importantes quanto o investimento em capital físico e, assim, o novo estado desenvolvimentista investiria também em educação, saúde e no fomento à inovação. $\mathrm{O}$ mesmo Peter Evans, que no seu livro citado acima falava de parceria entre o "Estado e a elite industrial", evoluiu para uma parceira mais ampla do Estado com a sociedade, já que caberia a sociedade decidir a alocação de recursos com maiores gastos com educação ao invés de maiores gastos no fomento ao investimento privado. Segundo Evans:

The confluence of endogenous growth theory with institutional approaches to development and the capability approach jibe nicely with the shifting historical context. Together they suggest that $21^{\text {st }}$ century development will depend on generating intangible assets (ideas, skills, and networks) rather than on stimulating investment in machinery and physical assets oriented to the production of tangible goods. This makes investment in human capabilities (which include what is traditionally known as "human capital") more economically critical. At the same time, new development theories assume that 
economic growth depends on political institutions and the capacity to set collective goals. The capability approach sets out the political argument most firmly, arguing that only public interchange and open deliberation can effectively define development goals and elaborate the means for attaining them. (EVANS, 2008b, p. 3).

Dado que voltamos a fazer políticas setoriais e o Estado passou novamente a financiar grandes projetos de infraestrutura via BNDES, sendo essas escolhas legítimas de um governo democrático, cabe a seguinte pergunta: o custo dessas políticas está sendo explicitado para a sociedade para que ela decida o que é prioritário, como seria de se esperar nesse modelo do "novo estado desenvolvimentista", ou o Estado faz uso de mecanismos de financiamento menos transparentes, tal como faz a China de hoje e que foi a marca do velho estado desenvolvimentista? Infelizmente, acredito que nos últimos anos caminhamos mais para este segundo caso. Alguns exemplos são suficientes para corroborar essa tese.

Primeiro, o falso dilema entre "fortalecimento" versus "não fortalecimento" do BNDES para que este possa aumentar os empréstimos para a indústria e infraestrutura. Essa política de fortalecimento do BNDES se deu por meio de empréstimos porque, neste caso, não há o impacto fiscal imediato dessas operações como ocorreria com uma capitalização pura e simples feita pelo Tesouro Nacional no BNDES. Nessas operações de empréstimos há a criação de um crédito e um débito que se compensam, mas como são corrigidos a taxas diferentes - o custo do débito (Selic) para o Tesouro Nacional muito maior que a remuneração do crédito (TJLP) paga pelo BNDES -, ao longo do tempo, a Dívida Liquida do Setor Público (DLSP) aumenta.

TABELA 5 - EMPRÉSTIMOS DO TESOURO NACIONAL PARA BANCOS PÚBLICOS (2006-2010) - R\$ MILHÕES

\begin{tabular}{|c|c|c|c|c|c|}
\hline & 2006 & 2007 & 2008 & 2009 & $2010 *$ \\
\hline Inst. Híbridos de Capital e Dívida & & 7.504 & 7.633 & 15.550 & 19.819 \\
\hline Créditos junto ao BNDES & & 0 & 35.454 & 129.237 & 235.932 \\
\hline TOTAL & & 7.504 & 43.087 & 144.787 & 255.751 \\
\hline
\end{tabular}

NOTA: * posição de outubro de 2010.

FONTE: Banco Central - Divída Liquida do Setor Público.

A Tabela 5 acima mostra que as operações de empréstimos do Tesouro Nacional passaram de "zero" para $\mathrm{R} \$ 255,7$ bilhões em quatro anos, o que mostra que essas operações tomaram vulto expressivo. Até outubro de 2010, em nenhum momento o governo divulgou o custo fiscal dessas operações, apenas os seus benefícios em entrevista coletiva em agosto de 2010. Dado que os técnicos do Tesouro Nacional são preparados e diariamente fazem projeções complicadíssimas, parece que se optou por "esconder" o custo dessas operações, o que torna difícil o debate quanto seus custos e benefícios, já que as operações de fortalecimento do 
BNDES passam a ideia, equivocada, de que não teriam custos para a sociedade e, assim, não haveria limite para esse tipo de política.

Segundo, como não há limite para o crescimento da dívida bruta do governo federal, o governo Lula não teve que se preocupar em definir fonte de recursos para fazer políticas setoriais para incentivar setores da indústria e aumentar o investimento público. No Brasil, é muito mais fácil expandir a dívida pública em $\mathrm{R} \$ 200$ bilhões para financiar novos programas setoriais do que aumentar os gastos anuais com educação em $\mathrm{R} \$ 0,5$ bilhão, já que neste caso a Lei de Responsabilidade Fiscal (Lei Complementar $n^{\circ}$ 101) exige a definição de uma fonte permanente de recurso e, no caso de novas emissões de dívida para que se faça política setorial via crédito subsidiado, não há essa exigência. Como não há uma explicitação dos custos das políticas setoriais, não se discute o uso alternativo desses recursos e, assim, o fomento setorial ainda toma uma importância maior do que o crescimento dos investimentos em educação, saúde e inovação. De acordo com o modelo do "novo estado desenvolvimentista", isso não deveria acontecer já que o investimento em capital humano é tão importante quanto o fomento ao capital físico.

Terceiro, além de não divulgar os custos do fortalecimento do BNDES, o governo passou a utilizar de subterfúgios para gerar um resultado primário artificial. Não há limite ótimo de endividamento nem tão pouco uma trajetória ideal de redução da DLSP, mas a redução do superávit primário e o aumento dos gastos com políticas setoriais, educação, saúde, segurança pública etc., deve ser discutida com a sociedade no âmbito da proposta orçamentária enviada ao Congresso Nacional. Uma das características do novo estado desenvolvimentista é justamente a maior transparência no uso de recursos públicos e na definição do que a sociedade considera prioritário. No entanto, ao invés de promover um debate aberto e transparente quanto à expansão dos gastos públicos e redução da economia do governo (resultado primário), o governo passou a aumentar os gastos e, ao mesmo tempo, gerar um primário real menor do que aquele estabelecido por ele próprio na Lei de Diretrizes Orçamentária (LDO). O melhor exemplo para essa prática de aumento de gastos e modificações no cálculo primário talvez seja a capitalização da Petrobras no segundo semestre de 2010 (ALMEIDA, 2010).

A operação original autorizada e discutida no Congresso Nacional era que o Tesouro Nacional faria cessão onerosa equivalente em até 5 bilhões de barris de petróleo, que ao preço fixado em setembro de 2010, seria equivalente a R \$ 74,8 bilhões. Essa operação significa que a União venderia o seu direito futuro de 5 bilhões de barris de petróleo para a Petrobras em troca de uma participação maior na empresa. Não haveria, hoje, a geração de receita para o governo. Na prática, o que aconteceu foi outra operação.

O Tesouro Nacional fez a cessão onerosa de barris de petróleo para a Petrobras no 
valor de $\mathrm{R} \$ 74,8$ bilhões. No entanto, ao invés de adquirir o equivalente em ações da companhia, como havia sido autorizado pelo Congresso Nacional, o Tesouro adquiriu apenas $\mathrm{R} \$ 42,9$ bilhões de ações da empresa. O saldo restante da cessão onerosa, equivalente R \$ 31,9 bilhões, foi paga pela Petrobras ao Tesouro Nacional com recursos da venda de ações para o Fundo Soberano e BNDES, que conseguiu um novo empréstimo do Tesouro para participar da capitalização da Petrobras. Essa operação, na prática, gerou uma receita primária de R \$ 31,9 bilhões para o Tesouro Nacional, receita extra que poderia ser utilizada para financiar qualquer despesa pública.

O governo transformou uma receita futura ( $\mathrm{R} \$ 74,8$ bilhões de petróleo) em ações da Petrobras ( $\mathrm{R} \$ 42,9$ bilhões) e outra parte ( $\mathrm{R}$ \$31,9 bilhões) em receita primária, em setembro de 2010, para ser gasta com qualquer coisa. Essa receita "extra" é, na verdade, a monetização de parte de uma receita futura, que jamais teve o seu uso discutido com o Congresso Nacional, o que mostra que as práticas de intervenção do Estado no Brasil do séc. XXI ainda lembram práticas associadas ao "ao modelo pouco transparente do velho estado desenvolvimentista".

O governo Lula foi eleito e constava no seu programa de governo a adoção de políticas setoriais. Assim, a opção de fortalecimento do BNDES e o retorno de políticas industriais foi uma operação legítima de um governo democraticamente eleito. O que não é legítimo é a decisão voluntária de não explicitar os custos das políticas setoriais para a sociedade, que para investir em educação e saúde precisa definir a fonte permanente de receita, não ocorrendo o mesmo para as políticas de apoio setorial executadas pelo BNDES.

A verdade é que, no segundo mandato do presidente Lula, alguns dos formuladores de política econômica pareciam acreditar que todos os problemas de crescimento do Brasil poderiam ser resolvidos pelo fortalecimento do BNDES, sem que se discutisse de quanto o banco precisaria para essa tarefa hercúlea. O principal funding do BNDES são os recursos do Fundo de Amparo ao Trabalhador (FAT) - 40\% da arrecadação anual do PIS/Pasep que é emprestada ao BNDES e paga ao longo do tempo à medida que o FAT necessite desses recursos. Na média de 2007 a 2009, os empréstimos do FAT ao BNDES foram de R \$10,9 bilhões, mas quando se computam os pagamentos do banco ao fundo, a entrada líquida de recursos ficou, na média, em só $\mathrm{R} \$ 2$ bilhões ao ano. Some-se a esses recursos o retorno dos investimentos antigos, que nos últimos três anos ficou na faixa de $\mathrm{R} \$ 50$ bilhões a $\mathrm{R} \$ 70$ bilhões, e temos um banco com um orçamento anual perto de $\mathrm{R} \$ 72$ bilhões, montante muito inferior ao que seria necessário para o BNDES continuar no ritmo de expansão que vem mostrando desde 2008. No período de 12 meses terminado em outubro de 2010, o BNDES havia desembolsado R $\$ 170,8$ bilhões, mais de duas vezes a real capacidade de empréstimo anual do banco. 
É claro que o BNDES tem outras fontes de recursos (carteira de renda variável, captação interna e externa), mas estes mal compensam os desembolsos do banco com serviços da dívida e com despesas tributárias e administrativas. Assim, sem recursos do Tesouro, o BNDES não tem capacidade de empréstimo anual muito acima de $\mathrm{R} \$ 70$ bilhões. Hoje, como se pode auferir da estrutura do passivo do BNDES abaixo, o banco tornou-se muito dependente de empréstimos do Tesouro Nacional, uma prática que não é sustentável no longo prazo já que baseia-se na expansão da dívida bruta, que tem um impacto financeiro no crescimento da DLSP.

GRÁFICO 2 - DÍVIDA DO BNDES COM O TESOURO NACIONAL - \% DO PASSIVO TOTAL

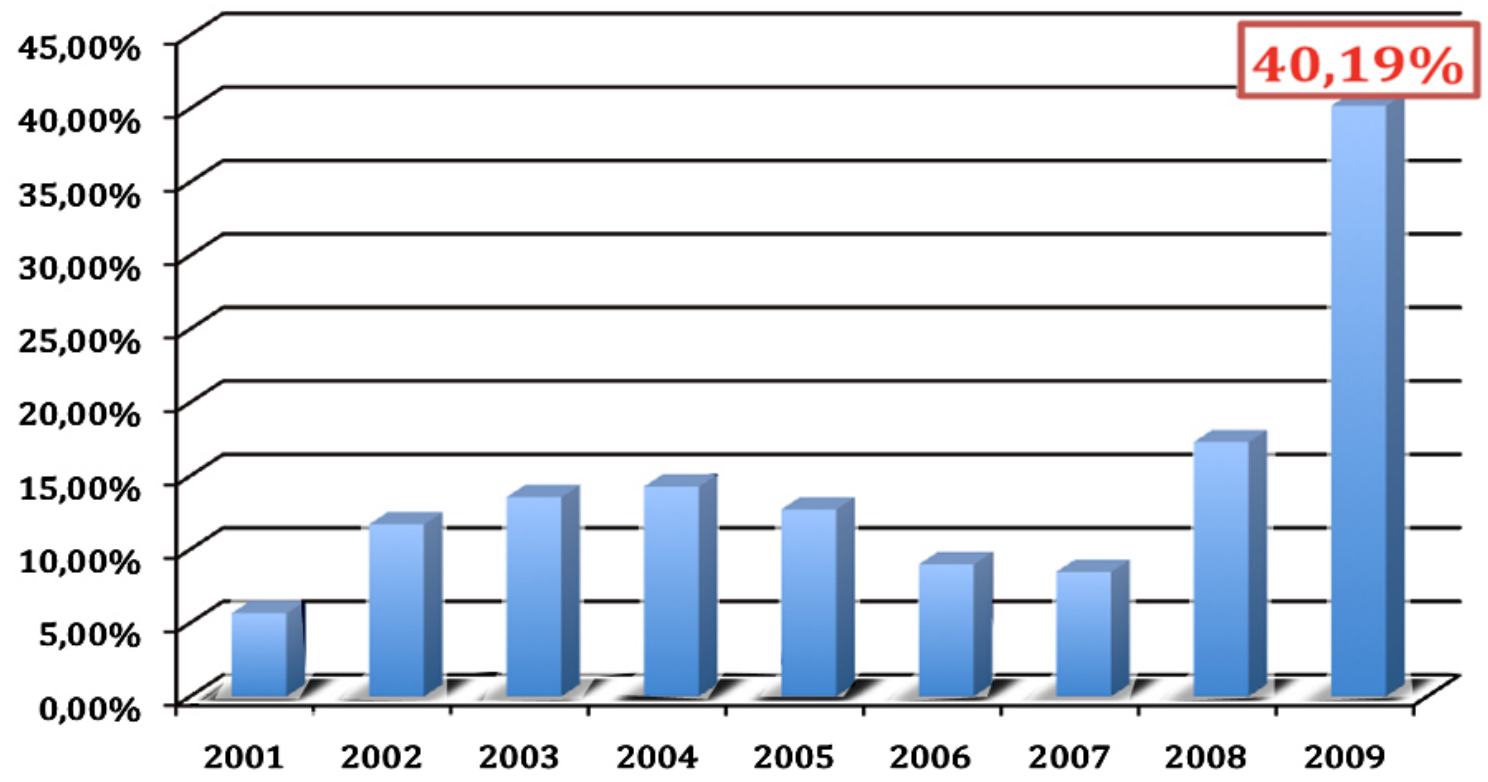

FONTE: BNDES.

Dado que o Brasil tem uma limitação de recursos para atender todas as demandas da sociedade, uma característica comum de todos os estado democráticos, uma discussão mais transparente com a sociedade poderia definir o que se quer do BNDES (ALMEIDA, 2010). Deve ser um banco voltado principalmente para o financiamento de projetos de infraestrutura? Que tipo de projetos? Qualquer projeto ou de preferência aqueles em que o retorno social seja maior que o privado? Que volume de recursos o banco deverá pôr à disposição para financiar as exportações e os investimentos de longo prazo? O BNDES deve financiar a internacionalização de empresas? Que tipo de empresas, em que condições e qual o volume de recursos alocados para essa finalidade? O BNDES deve financiar operações de fusões e aquisições? Em que setores e por quê?

Enquanto as perguntas acima não forem adequadamente respondidas, a definição do novo estado desenvolvimentista que incentiva não apenas capital físico, mas também o capital 
humano e inovação, será um modelo mais consistente no papel do que na prática real das políticas de desenvolvimento, que ainda abusam da falta de transparência e do dirigismo típico do velho estado desenvolvimentista. O que tem sido feito no Brasil nos último anos via BNDES é aumentar a dívida para aumentar o investimento público e privado, algo que já fizemos na segunda metade dos anos 70 no âmbito do "velho estado desenvolvimentista".

\section{CONCLUSÃO}

Esse texto mostrou que apesar da eleição de um governo de esquerda em 2002 e da promessa de práticas mais transparentes na definição de prioridades para o gasto público, tanto na área fiscal quanto na área de políticas setoriais, há mais continuidade do que ruptura. Os vários governos brasileiros fizeram um grande esforço para melhorar a gestão e o resultado fiscal desde a segunda metade dos ano 80, mas as medidas institucionais na área fiscal não foram suficientes para controlar a expansão do gasto público nos anos que se seguiram à promulgação da Constituição Federal em 1988.

Os dados fiscais para o Brasil mostram uma expansão quase contínua das transferências (INSS e sociais), e esse padrão não foi alterado no governo Lula. Da mesma forma que nos anos 90, o investimento público da União no governo Lula foi em média inferior a 1\% do PIB e os gastos com INSS continuaram a puxar o crescimento do gasto não financeiro junto com os gastos sociais. Esse modelo levou a novos aumentos da carga tributária, que é o outro lado de uma forte política de valorização do salário mínimo.

No caso das políticas setoriais, esse texto explicou que a atual política industrial brasileira, a PDP de 2008, baseia-se numa visão pragmática na qual todos os setores são incentivados e contam com algum suporte do governo. Essa modificação da política industrial decorreu, como se argumentou no texto, do desafio de justificar uma política industrial em uma economia com uma estrutura diversificada como a brasileira, em um contexto democrático, onde o apoio à essa política é maior quanto mais abrangente ela for. Assim, a Política de Desenvolvimento Produtivo (PDP) é uma política industrial que, justamente por não fazer escolha de setores a serem incentivados, conta com o apoio amplo da classe empresarial.

Mostrou-se também que, apesar do discurso pró-inovação e da importância de investimento em educação, a política industrial real toma a forma de uma política de incentivos voltados para a constituição de empresas globais, com o apoio do BNDES aos processos de F\&A em vários setores. Apesar desse processo de F\&A resultar em ganhos imediatos para algumas empresas e setores, ele ajuda a consolidar a atual estrutura produtiva brasileira e a nossa atual inserção internacional. Adicionalmente, ainda não são claros os custos desse novo papel mais 
ativo do Estado brasileiro na economia.

As políticas setoriais modernas no âmbito do que passou a ser chamado de "novo estado desenvolvimentista" ainda carecem de transparência quanto ao seu custo. Não se sabe se os benefícios sociais da estratégia de formação de empresas multinacionais brasileiras traz ganhos sociais maiores que os benefícios privados e não há mecanismos de avaliação das empresas incentivadas. Essa discussão torna-se ainda mais importante quando se leva em conta que, atualmente, o governo brasileiro tem se endividado para emprestar recursos para o BNDES continuar a execução da política industrial.

Em 2009, o governo federal emprestou R $\$ 100$ bilhões ao BNDES, sendo complementado por $\mathrm{R} \$ 80$ bilhões, em 2010, mais $\mathrm{R} \$ 25$ bilhões para que o BNDES participasse da capitalização da Petrobras, mais $\mathrm{R} \$ 20$ bilhões para o projeto do trem-bala e, possivelmente, mais $\mathrm{R} \$ 60$ bilhões para 2011. Como se sabe, a fonte de recursos mais importante do BNDES são os empréstimos do Fundo de Amparo ao Trabalhador (FAT), mas este fundo tornou-se pequeno para o tamanho atual do BNDES. Assim, nas condições atuais, o fortalecimento do BNDES leva, necessariamente, a um aumento da dívida do governo federal e, portanto, é preciso que se avalie os prós e contras da atual política industrial, como seria esperado da maior transparência que se aguarda do "novo estado desenvolvimentista".

\section{REFERÊNCIAS}

ALMEIDA, M. A real política industrial brasileira do séc. XXI. Brasília: IPEA, 2009 (Texto para Discussão, 1452).

ALMEIDA, M. A Constituição de 1988 e as políticas de incentivo à ciência e tecnologia. In: CARDOSO JR., J. C. (Org.) A Constituição Brasileira de 1988 Revisitada. v. 1. Brasília: IPEA, 2009, p. 213-250.

ALMEIDA, M. O que queremos do BNDES. Estado de São Paulo, São Paulo, ago. 2010.

ALMEIDA, M. Superávit primário: descanse em paz. Valor Econômico, São Paulo, out. 2010.

ALMEIDA, M.; GIAMBIAGI, F.; PESSOA, S. Expansão e dilemas no controle do gasto público federal. Boletim de Conjuntura IPEA, Brasília, n. 73, jun. 2006.

ALMEIDA, M.; PESSOA, S. Os dilemas do gasto público. Valor Econômico, São Paulo, mar. 2010.

AMSDEN, A. Asia's next giant: South Korea and late industrialization. New York: Oxford University Press, 1989.

AMSDEN, A. The rise of the rest: challenges to the west from late-industrializing economies. New York: Oxford University Press, 2001.

DRESSER, D. Carta abierta a Carlos Slim. Revista Processo, México, feb. 2009. 
EVANS, P. Embedded autonomy: states \& industrial transformation. Princeton: Princeton University Press, 1995.

EVANS, P. Constructing the $21^{\text {st }}$ century developmental state: potentialities and pitfalls. the role of government in Hong Kong. Hong Kong: University of Hong Kong Press, 2008.

EVANS, P. In search of the $21^{\text {st }}$ century developmental state. Centre for Global Political Economy at the University of Sussex Working Paper, n. 4, 2008.

FIESP. Avaliação da política de desenvolvimento produtivo - PDP. Cadernos de Política Industrial, n. 1, 2008. Disponível em: < http://www.fiesp.com.br/competitividade/downloads/ pdp_decomtec.pdf>.

FLEURY, A.; FLEURY, M. T. L. Por uma política industrial desenhada a partir do tecido industrial. In: Política Industrial. São Paulo: PubliFolha, 2004.

KOHLI, A. State-directed development: political power and industrialization in the global periphery. New York: Cambridge University Press, 2004.

KRUGMAN, P.; OBSTFELD, M. Economia internacional: teoria e política. São Paulo: Pearson Education, 2001.

LINDERT, P. H. Growing public: social spending and economic growth since the eighteenth century. Cambridge: Cambridge University Press, 2004.

LUCAS, R. On the mechanics of economic development. Journal of Monetary Economics, v. 22, p. 3-42, 1988.

PUGA, F.; MEIRELLES, B. Perspectivas de investimento na indústria em 2010-2013. Visão do Desenvolvimento, n. 79, mar. 2010.

RODRICK, D. Trade and industrial policy reform. Elsevier Science, 1995.

RODRICK, D. Industrial policy for the twenty-first century, 2004. Disponível em: <http://ksghome.harvard.edu/ $\sim$ drodrik/papers.html $>$.

ROMER, P. Increasing returns and long-run growth. Journal of Political Economy, p. 10021037, 1986.

SCHNEIDER, B. R. Big bussiness in Brazil: leveraging natural endowments and state support for international expasion. In: BRAINARD, L.; MARTINEZ-DIAZ, L. (Eds.) Brazil as an emerging economic superpower? Understanding Brazil's changing role in the global economy. Washington: The Brookings Institution, 2009.

TRUBEK, D. Developmental states and the legal order: towards a new political economy of development and law. 2010. Mimeo.

WRIGHT, L. Você conhece esse cara? Revista Piauí, ago. 2009. 
ANEXO I - GASTO PÚBLICO FEDERAL NÃO FINANCEIRO (1991-2009) - \% DO PIB

\begin{tabular}{|c|c|c|c|c|c|}
\hline & $\begin{array}{c}\text { Transferências } \\
\text { a estados e mu- } \\
\text { nicípios }\end{array}$ & Pessoal & Benefícios INSS & Outros & Total \\
\hline 1991 & 2,6 & 3,8 & 3,4 & 3,9 & 13,7 \\
\hline 1991-1995 & 2,7 & 4,6 & 4,5 & 3,8 & 15,6 \\
\hline 1996-2000 & 3,2 & 5,0 & 5,7 & 5,0 & 18,9 \\
\hline 2001 & 3,5 & 4,8 & 5,8 & 5,0 & 19,1 \\
\hline 2002 & 3,8 & 4,8 & 6,0 & 5,0 & 19,5 \\
\hline 2003 & 3,5 & 4,5 & 6,3 & 4,4 & 18,7 \\
\hline 2004 & 3,5 & 4,3 & 6,5 & 4,8 & 19,1 \\
\hline 2005 & 3,9 & 4,3 & 6,8 & 5,3 & 20,3 \\
\hline 2006 & 3,9 & 4,5 & 7,0 & 5,5 & 20,9 \\
\hline 2007 & 4,0 & 4,4 & 7,0 & 5,8 & 21,1 \\
\hline 2008 & 4,4 & 4,4 & 6,6 & 5,6 & 21,0 \\
\hline 2009 & 4,1 & 4,8 & 7,1 & 6,3 & 22,3 \\
\hline Crescimento & 12 & 10 & 26 & 11 & 58 \\
\hline $\begin{array}{l}\text { 1991-2002 } \\
\text { Crescimento }\end{array}$ & 1,2 & 1,0 & 2,0 & 1,1 & , , \\
\hline 2003-2009 & 0,3 & 0,0 & 1,1 & 1,3 & 2,8 \\
\hline $\begin{array}{l}\text { Crescimento } \\
1991-2009\end{array}$ & 1,5 & 1,0 & 3,7 & 2,4 & 8,6 \\
\hline
\end{tabular}

FONTE: Almeida, M.; Giambiagi, F; Pessoa, S. (2006); SIAFI. 
